OPEN ACCESS

Edited by:

Seitaro Nomura,

The University of Tokyo, Japan

Reviewed by:

Robert Kelly,

UMR7288 Institut de Biologie du Développement de Marseille (IBDM), France Patrick G. Burgon,

Qatar University, Qatar

*Correspondence: Hiroyuki Yamagishi

hyamag@keio.jp

tThese authors have contributed equally to this work

Specialty section:

This article was submitted to Cardiovascular Genetics and Systems Medicine,

a section of the journal Frontiers in Cardiovascular Medicine

Received: 14 January 2021 Accepted: 22 February 2021 Published: 16 March 2021

Citation:

Kodo K, Uchida K and Yamagishi H (2021) Genetic and Cellular Interaction During Cardiovascular Development Implicated in Congenital Hear Diseases.

Front. Cardiovasc. Med. 8:653244.

doi: 10.3389/fcvm.2021.653244

\section{Genetic and Cellular Interaction During Cardiovascular Development Implicated in Congenital Heart Diseases}

\author{
Kazuki Kodo ${ }^{\dagger}$, Keiko Uchida ${ }^{\dagger}$ and Hiroyuki Yamagishi ${ }^{\star \dagger}$ \\ Division of Pediatric Cardiology, Department of Pediatrics, Keio University School of Medicine, Tokyo, Japan
}

Congenital heart disease (CHD) is the most common life-threatening congenital anomaly. $\mathrm{CHD}$ occurs due to defects in cardiovascular development, and the majority of $\mathrm{CHDs}$ are caused by a multifactorial inheritance mechanism, which refers to the interaction between genetic and environmental factors. During embryogenesis, the cardiovascular system is derived from at least four distinct cell lineages: the first heart field, second heart field, cardiac neural crest, and proepicardial organ. Understanding the genes involved in each lineage is essential to uncover the genomic architecture of CHD. Therefore, we provide an overview of recent research progress using animal models and mutation analyses to better understand the molecular mechanisms and pathways linking cardiovascular development and CHD. For example, we highlight our recent work on genes encoding three isoforms of inositol 1,4,5-trisphosphate receptors $\left(\mathrm{IP}_{3} \mathrm{R} 1,2\right.$, and 3$)$ that regulate various vital and developmental processes, which have genetic redundancy during cardiovascular development. Specifically, $\mathrm{IP}_{3} \mathrm{R} 1$ and 2 have redundant roles in the atrioventricular cushion derived from the first heart field lineage, whereas $I P_{3} R 1$ and 3 exhibit redundancy in the right ventricle and the outflow tract derived from the second heart field lineage, respectively. Moreover, 22q11.2 deletion syndrome (22q11DS) is highly associated with CHD involving the outflow tract, characterized by defects of the cardiac neural crest lineage. However, our studies have shown that TBX1, a major genetic determinant of 22q11DS, was not expressed in the cardiac neural crest but rather in the second heart field, suggesting the importance of the cellular interaction between the cardiac neural crest and the second heart field. Comprehensive genetic analysis using the Japanese genome bank of $\mathrm{CHD}$ and mouse models revealed that a molecular regulatory network involving GATA6, FOXC1/2, TBX1, SEMA3C, and FGF8 was essential for reciprocal signaling between the cardiac neural crest and the second heart field during cardiovascular development. Elucidation of the genomic architecture of $\mathrm{CHD}$ using induced pluripotent stem cells and next-generation sequencing technology, in addition to genetically modified animal models and human mutation analyses, would facilitate the development of regenerative medicine and/or preventive medicine for $\mathrm{CHD}$ in the near future.

Keywords: heart field, neural crest, outflow tract, inositol trisphosphate receptor, TBX1, 22q11.2 deletion 


\section{INTRODUCTION}

Congenital heart disease (CHD) is the most common lifethreatening congenital anomaly that occurs in $\sim 1 \%$ of live births. With advances in pediatric cardiology and cardiac surgery, most patients with CHD survive to adulthood; therefore, understanding the inheritance of $\mathrm{CHD}$ has become an increasingly critical clinical issue. Although insight gleaned from molecular genetics combined with developmental biology approaches has helped to uncover the detailed mechanisms of cardiovascular development, the genomic architecture of CHD remains largely unknown. We provide an overview of the progress that research has made till date in understanding the molecular mechanisms contributing to cardiovascular development, which in turn can provide new directions for research to uncover the inheritance of CHD and key susceptibility genes. We first provide general background into the etiology of CHD and the nature of cardiac development, highlighting our work on the role of inositol 1,4,5-trisphosphate receptors $\left(\mathrm{IP}_{3} \mathrm{Rs}\right)$ in this process. In addition, we focus on recent research demonstrating a mechanistic link of the Tbox-containing transcription factor (TBX1) with CHD in the context of 22q11.2 deletion syndrome (22q11DS). Finally, we highlight progress to date in understanding the general genetic architecture associated with $\mathrm{CHD}$ and the underlying regulatory mechanisms.

\section{ETIOLOGY OF CHD}

CHD is considered to occur due to defects in cardiovascular development during the first 6 weeks of gestation. At this stage, the heart and vessels develop from a simple primitive tube structure into a four-chambered heart with two great vessels. Genetic factors, including chromosomal abnormalities, are estimated to account for approximately $8 \%$ of CHD cases, with single-gene mutations accounting for about $5 \%$ of cases, and environmental factors, including maternal infections, systemic diseases, and administration of drugs, accounting for about $2 \%$ of CHD cases. However, the etiology of the remaining $\sim 85 \%$ of CHDs is generally unknown, and is therefore attributed to so-called "multifactorial inheritance," which refers to the interaction between certain genetic and environmental factors $(1,2)$. Recently, more genetic factors associated with CHD have been reported, including chromosomal abnormalities for $12 \%$ of cases, de novo copy number variants such as chromosomal microdeletion accounting for $15 \%$ of cases and de novo gene mutation affecting protein function in 10\% of cases, and inherited gene mutations in $1.3 \%$ of cases (Tables 1, 2) (3-5). As shown in Tables 1, 2, candidate monogenic factors include many transcription factors and signal molecules that are essential for development of the heart and are responsible for multiple types of CHD. Genetic alterations of these factors are considered to disrupt the spatiotemporal regulation of complex threedimensional heart structure. However, the interaction of multiple genetic and environmental factors is still considered as the primary etiology of the remaining majority of CHDs.

\section{DEVELOPMENTAL ORIGINS OF THE CARDIOVASCULAR SYSTEM}

Current knowledge in molecular embryology suggests that the cardiovascular system is derived from at least four distinct cell lineages, namely, the first heart field (FHF), second heart field (SHF), cardiac neural crest (CNC), and proepicardial organ (PEO) (Figure 1) (6-9). The FHF stands for the crescent shaped heart primordium that is derived from the anterior lateral plate mesoderm. The FHF cells (shown in red in Figure 1) form a primitive straight heart tube, consisting of an interior endocardial layer and an exterior myocardial layer along with cardiac jelly (extracellular matrix) layer in between. In addition to the FHF, the SHF (shown in blue in Figure 1) develops medially to the cardiac crescent from the splanchnic mesoderm and lies along the pharyngeal region dorsal to the primitive heart tube derived from the FHF (10-12). Eventually, the heart tube provides a scaffold and cardiac progenitor cells derived from the SHF migrate into both anterior and posterior ends of it. The heart tube proceeds looping rightward, the cells originally from the FHF finally form exclusively the left ventricle and part of the atria, whereas cells from the SHF migrated into the anterior portions of the heart tube form a large portion of the outflow tract of and the right ventricle. In addition, cells from the SHF cross the pharyngeal mesoderm into the posterior end of the heart tube contribute to a part of the atria. Meanwhile, CNC cells (shown in yellow in Figure 1), specifically developed in the dorsal region of the neural tube between the mid-otic placode and the third somite, migrate to the outflow tract where they give rise to the outflow tract septum to separate the truncus arteriosus into the aorta and pulmonary artery (13-15). CNC cells also migrate to pharyngeal arch arteries 3 , 4 , and 6 , where they differentiate into smooth muscle cells of the great vessels. The neural crest cells from the preotic region of the neural tube contribute to the development of coronary arteries (16). The PEO (shown in green in Figure 1) is derived from the coelomic mesothelium that overlays the liver bud and gives rise to the epicardial layer over the heart (12). Some epicardial cells invade the subepicardial space through a process of epithelial-mesenchymal transformation, and contribute to the development of the coronary vessels and connective tissues $(17,18)$. To further uncover the genetic architecture of CHD, it is essential to adopt an approach for identifying the specific genes involved in each of these progenitor cell lineages, and to determine how their interaction regulates cardiovascular development.

\section{$I_{3}$ Rs IN CARDIOVASCULAR DEVELOPMENT}

We have investigated the roles of three isoforms of $\mathrm{IP}_{3} \mathrm{R}$ $\left(\mathrm{IP}_{3} \mathrm{R} 1,2\right.$, and 3$)$ in cardiovascular development, demonstrating their genetic redundancy (Figure 2). In particular, $\mathrm{IP}_{3} \mathrm{R} 1$ and 2 have redundant roles in the FHF-derived lineage, whereas $\mathrm{IP}_{3} \mathrm{R} 1$ and 3 exhibit redundancy in SHF-derived lineages. $\mathrm{IP}_{3} \mathrm{Rs}$ are intracellular $\mathrm{Ca}^{2+}$-release channels, which are opened by 
TABLE 1 | Genetic causes of non-syndromic congenital heart diseases.

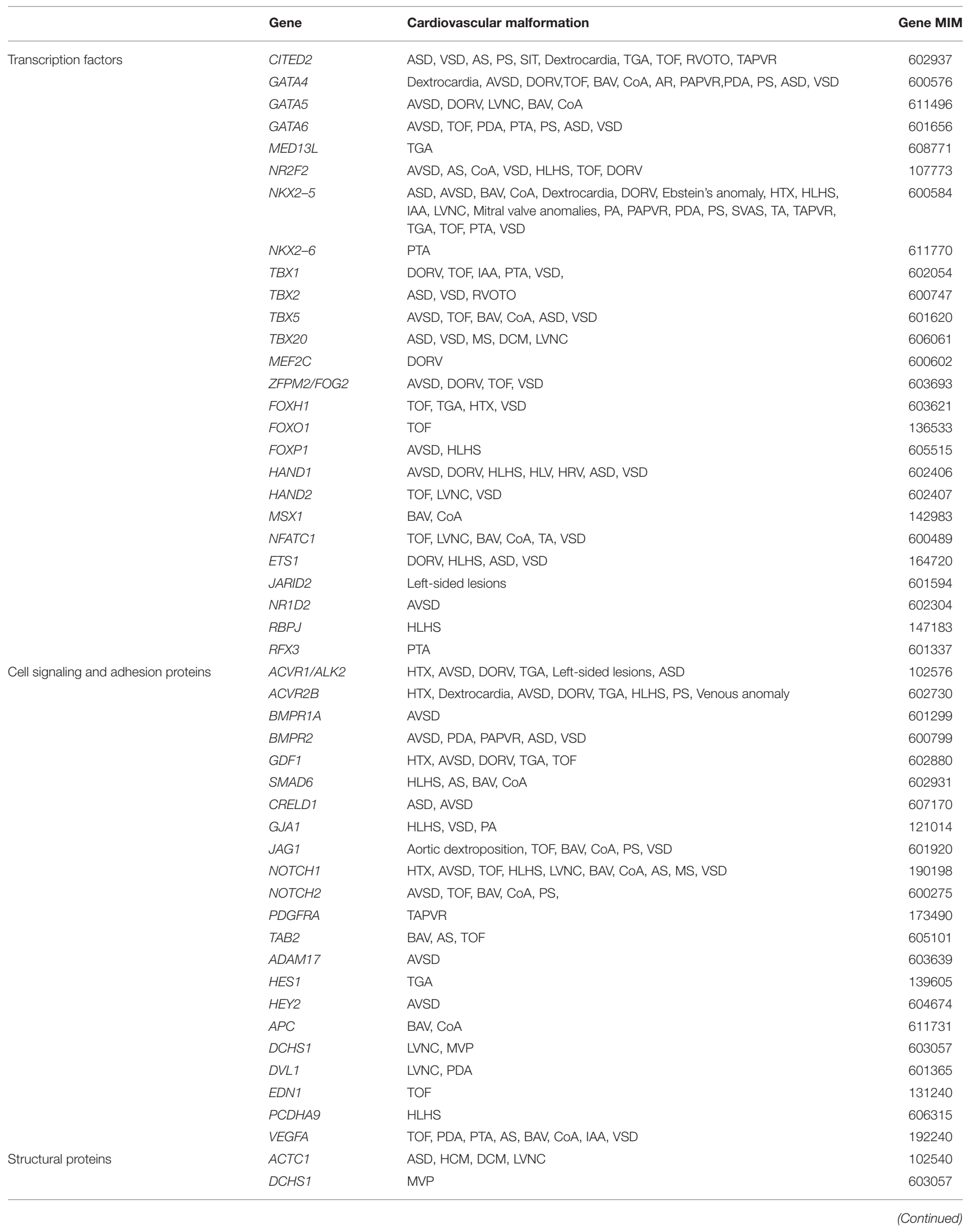


TABLE 1 | Continued

\begin{tabular}{lll}
\hline Gene & Cardiovascular malformation & Gene MIM \\
\hline ELN & SVAS & 130160 \\
MYH6 & ASD, HCM, DCM & 160710 \\
MYH7 & Ebstein's anomaly, LVNC, HCM, DCM & 160760 \\
MYH11 & PDA, TAA & 160745
\end{tabular}

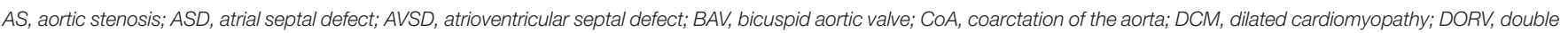

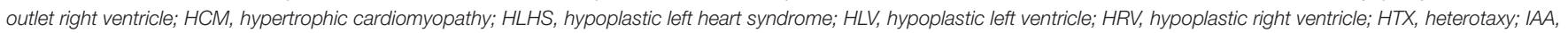

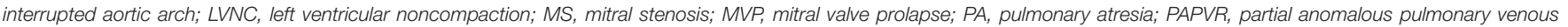

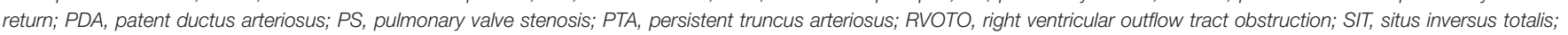

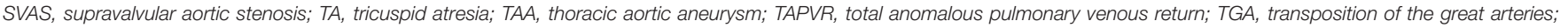
TOF, tetralogy of Fallot; VSD, ventricular septal defect.

TABLE 2 | CNVs associated with CHD.

\begin{tabular}{|c|c|c|c|c|c|c|}
\hline Locus & Size (kb) & Mode & CNV & Copy number & Candidate genes for CHD & Type of CHD \\
\hline $1 q 21.1$ & $418-3,981$ & de novo, inherited, n/a & Gain, Loss & $3-45$ & $\begin{array}{l}\text { PRKAB2, FM05, CHD1L, BCL9, ACP6, } \\
\text { GJA5, CD160, PDZK1, NBPF11, JM05, } \\
\text { GJA8 }\end{array}$ & TOF, AS, COA, PA, VSD \\
\hline 3p25.1 & $175-12,380$ & de novo, inherited & Gain & 2 & RAFJ, TMEM4O & TOF \\
\hline $3 q 22.1-3 q 26.1$ & $680-32134$ & inherited, n/a & Gain, Loss & $0-300$ & $\begin{array}{l}\text { FOXL2, NPHP3, FAM62C, CEP70, FAIM, } \\
\text { PIK3CB, FOXL2, BPESC1 }\end{array}$ & DORV, TAPVR, AVSD \\
\hline $4 q 22.1$ & 45 & de novo & Gain & 1 & PPM1K & TOF \\
\hline $5 q 14.1-q 14.3$ & $4937-5454$ & Inherited, de novo & Gain & 41,103 & EDIL3, VCAN, SSBP2, TMEM167A & TOF \\
\hline $5 q 11.1$ & 0.6 & de novo & Gain & 1 & ISL1 & TOF \\
\hline $5 q 35.3$ & $264-1777$ & de novo, n/a & Gain & 19-38 & $\begin{array}{l}\text { CNOT6, GFPT2, FLT4, ZNF879, ZNF 345C, } \\
\text { ADAMTS2, NSD1 }\end{array}$ & TOF \\
\hline $7 q 11.23$ & $330-348$ & $\mathrm{n} / \mathrm{a}$ & Gain & $5-8$ & FKBP6 & HLHS, Ebstein \\
\hline 8p23.1 & $67-12,000$ & $\mathrm{n} / \mathrm{a}$ & Gain, Loss & 4 & GATA4,NEIL2, FDFT1, CSTB, SOX7 & $\begin{array}{l}\text { AVSD, VSD, TOF, ASD, } \\
\text { BAV }\end{array}$ \\
\hline 9q34.3 & $190-263$ & de novo & Loss & $2-9$ & NOTCH1, EHMT1 & TOF, COA, HLHS \\
\hline $9 q 34.3$ & 1.7 & de novo & Gain & 1 & NOTCH1 & TOF \\
\hline $11 p 15.5$ & $256-271$ & $\mathrm{n} / \mathrm{a}$ & Gain & 13 & HRAS & SV, AS \\
\hline $13 q 14.11$ & $55-1430$ & $\mathrm{n} / \mathrm{a}$, de novo & Gain & 7 & TNFSF11 & TOF, TAPVR, VSD, BAV \\
\hline $15 q 11.2$ & $238-2,285$ & $\mathrm{n} / \mathrm{a}$ & Loss & 4 & TUBGCP5, CYFIP1, NIPA2, NIPA1 & COA, ASD, VSD, TAPVR \\
\hline $16 p 13.11$ & $1414-2903$ & $\mathrm{n} / \mathrm{a}$ & Gain & $11-14$ & MYH11 & HLHS \\
\hline $18 q 11.1-2$ & $308-6118$ & $\mathrm{n} / \mathrm{a}$ & Gain & $1-28$ & GATA6 & VSD \\
\hline $19 p 13.3$ & $52-805$ & $\mathrm{n} / \mathrm{a}$, de novo & Gain, Loss & $1-34$ & $\begin{array}{l}\text { MIER2, CNN2, FSTL3, PTBP1, WDR18, } \\
\text { GNA11, S1PR4 }\end{array}$ & TOF \\
\hline $22 \mathrm{q} 11.21$ & $0.7-13$ & de novo & Gain & 1 & PRODH & TOF \\
\hline Xp22.2 & $509-615$ & $\mathrm{n} / \mathrm{a}$ & Gain & $2-4$ & MID1 & TOF, AVSD \\
\hline
\end{tabular}

CNV, copy number variation; CHD, congenital heart disease; ASD, atrial septal defect; VSD, ventricular septal defect; PDA, patent ductus arteriosus; TOF, tetralogy of Fallot; COA,

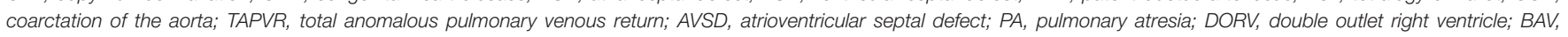
bicuspid aortic valve; HLHS, hypoplastic left heart syndrome; AS, aortic stenosis; SV, single ventricle.

$\mathrm{IP}_{3}$ binding to regulate various vital processes for diverse cell functions (19). As the modifications distinguishing the isoforms vary, such as phosphorylation sites, splicing sites, and associated molecules, each $\mathrm{IP}_{3} \mathrm{R}$ may play a distinct role as a signaling hub offering different trajectories of cell signaling (20). In cardiovascular development, expression of $\mathrm{IP}_{3} \mathrm{R} 1$ was detectably higher in the atrial than in the ventricular myocardium, $\mathrm{IP}_{3} \mathrm{R} 2$ was mainly expressed in the trabecular layer of the ventricular myocardium, and $\mathrm{IP}_{3} \mathrm{R} 3$ was uniformly expressed in the atrial and ventricular myocardia from embryonic day 9.5. These dynamic and complementary expression patterns of each subtype of $\mathrm{IP}_{3} \mathrm{R}$ suggest their specific and/or redundant functions during the development of the heart. Although single subtype-knockout mice showed no developmental disorders and could survive after birth, $\mathrm{IP}_{3} \mathrm{R} 1-\mathrm{IP}_{3} \mathrm{R} 2$ double-knockout mice died in utero with developmental defects of the ventricular myocardium and atrioventricular canal of the heart, along with impaired $\mathrm{Ca}^{2+}$-dependent calcineurin/NFATc signaling by embryonic day 11.5 (21). Moreover, $\mathrm{IP}_{3} \mathrm{R} 1-\mathrm{IP}_{3} \mathrm{R} 3$ double-knockout embryos showed hypoplasia of the outflow tract and the right ventricle, 


\section{First heart field \\ - Second heart field \\ $\square$ Cardiac neural crest \\ $\square$ Proepicardium} embryo, then move ventrally to the midline and form a linear heart tube. The second heart field (blue) is situated in the medial splanchnic pharyngeal mesoderm, and migrates to the anterior and posterior parts of the linear heart tube, providing the source of the right ventricle, outflow tract, and atrial cardiomyocytes. After looping of the heart tube, cardiac neural crest cells (yellow) migrate from the dorsal neural tube to pharyngeal arch arteries III, IV, and VI, and contribute to vascular smooth muscle cells of the aortic arch and the cardiac outflow tract. At the same time, the progenitor cells from proepicardial organ (green) contact the surface of the developing heart, giving rise to the epicardium.

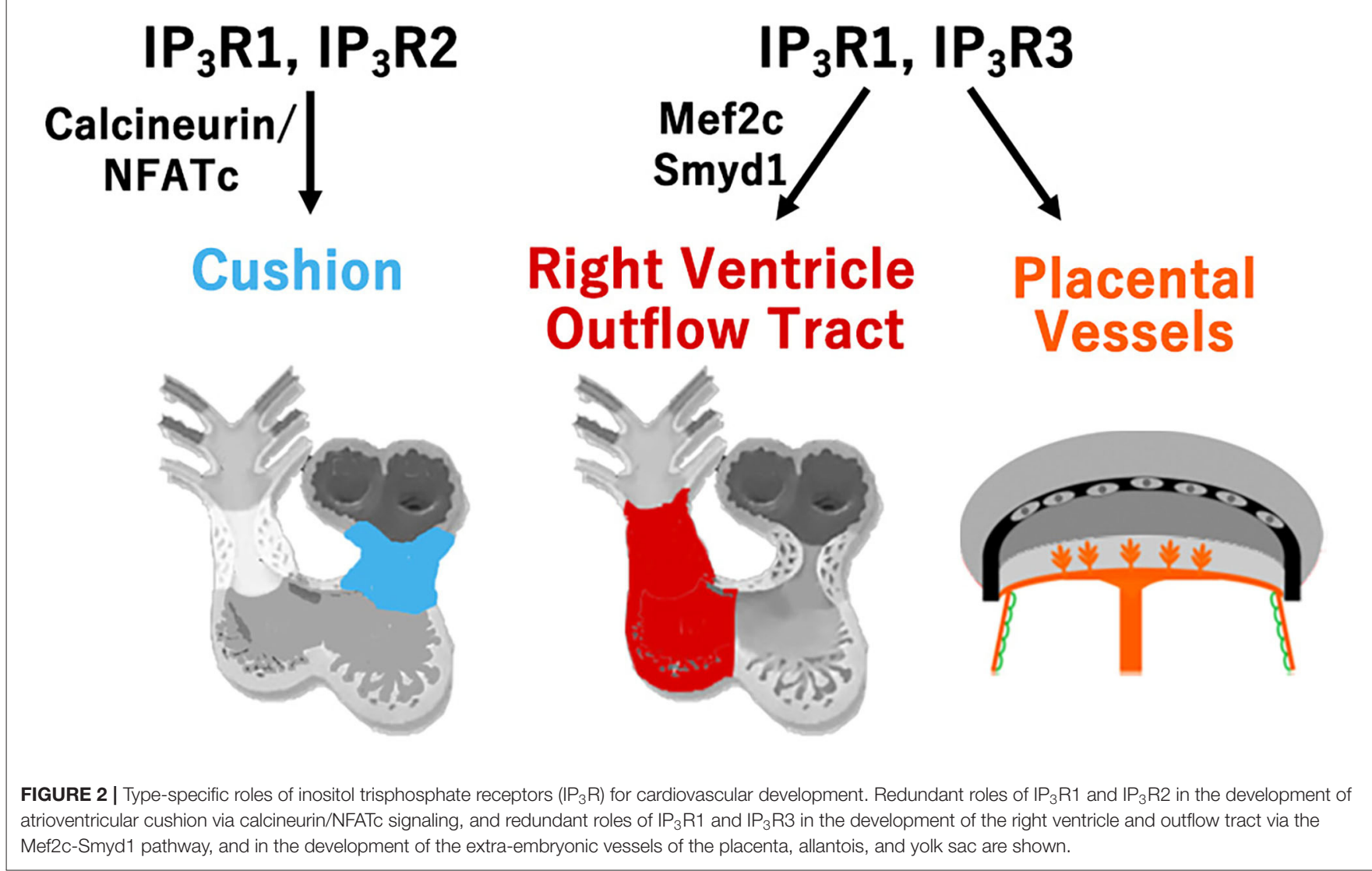

reduced expression of specific molecular markers, and enhanced apoptosis of mesodermal cells in the SHF with reduced activity of the Mef2C-Smyd1 pathway, a transcriptional cascade essential for the SHF (22). In addition, $\mathrm{IP}_{3} \mathrm{R} 1$ and $\mathrm{IP}_{3} \mathrm{R} 3$ were found to be required for extra-embryonic vascularization in the placenta, allantois, and yolk sac at the embryonic-maternal interface (23).

\section{GENOMIC ARCHITECTURE OF CHD IMPLICATED WITH 22Q11.2 DELETION SYNDROME}

22q11DS is the most common chromosomal microdeletion syndrome and is also known as DiGeorge syndrome or Takao syndrome $(24,25)$. 22q11DS is highly associated with 


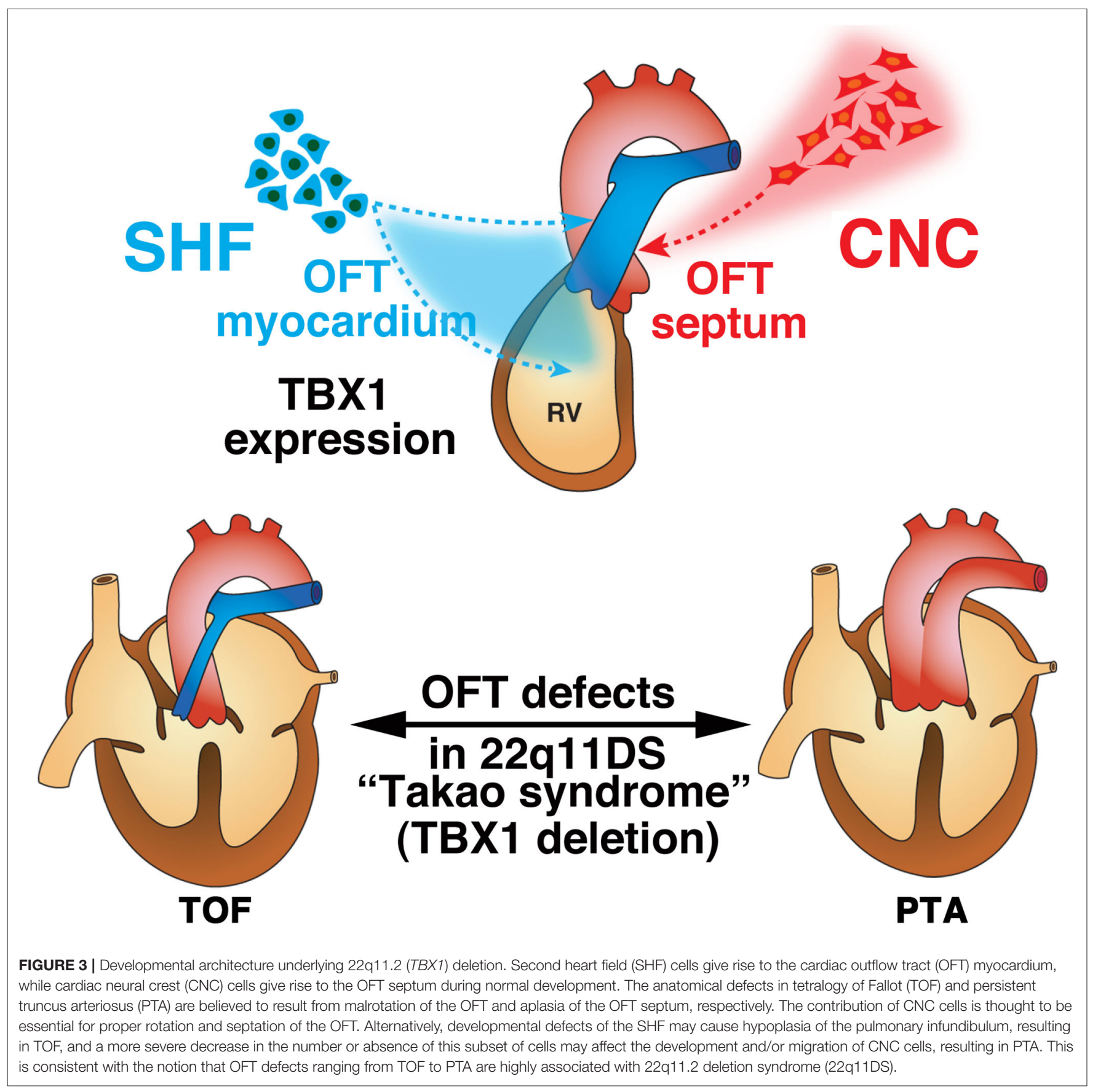

$\mathrm{CHD}$, involving the outflow tract, including persistent truncus arteriosus (PTA) and tetralogy of Fallot (TOF). Based on observations from experimental ablation of the $\mathrm{CNC}$ in chicken embryos, the outflow tract defects implicated in 22q11DS were thought to be the primary defect of the $\mathrm{CNC}$ development that leads to the outflow tract septum of the heart. At the beginning of the twenty-first century, the transcription factor TBX1 was identified to be the major etiology of outflow tract defects in this syndrome using new genetic engineering methods to model 22q11DS in mice (26-28). Mice with null or hypomorphic mutations for Tbx1 demonstrate PTA $(28,29)$. Delineation of the expression pattern of TBX1 shed further light on the molecular and cellular basis of normal and abnormal development of the outflow tract. We and other groups surprisingly revealed that TBX1 was not expressed in the $\mathrm{CNC}$, but was robustly expressed in the core region of pharyngeal mesoderm in the pharyngeal arch as well as in the SHF, pharyngeal endoderm, and head mesenchyme (30-32). Moreover, we showed that TBX1expressing descendants that represent a subset of cells originated from the SHF, predominantly contribute to the right ventricular 

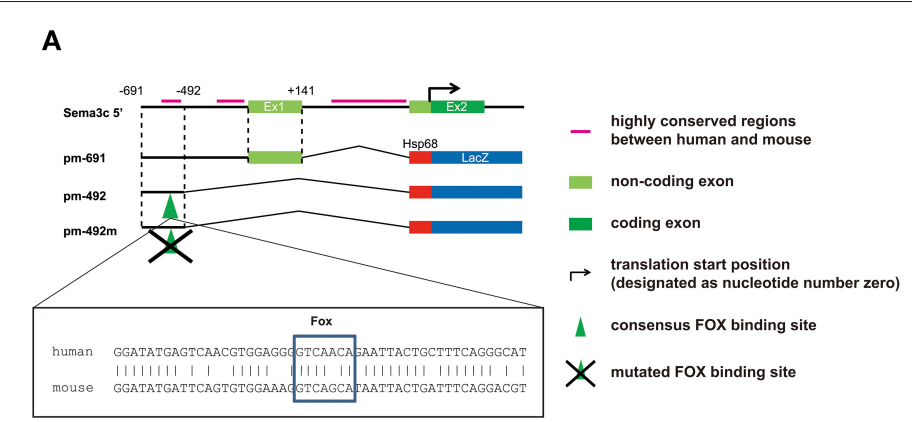

B
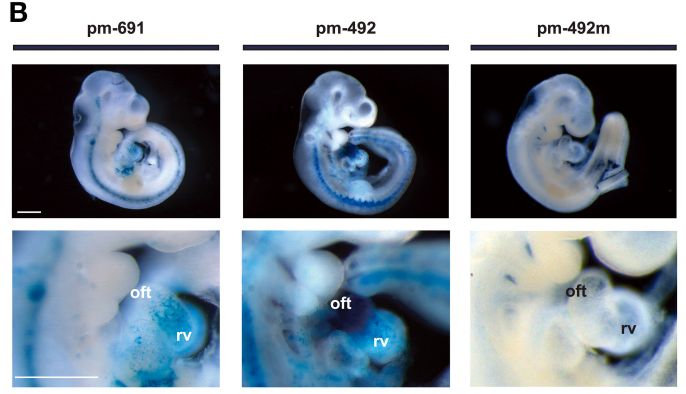

C
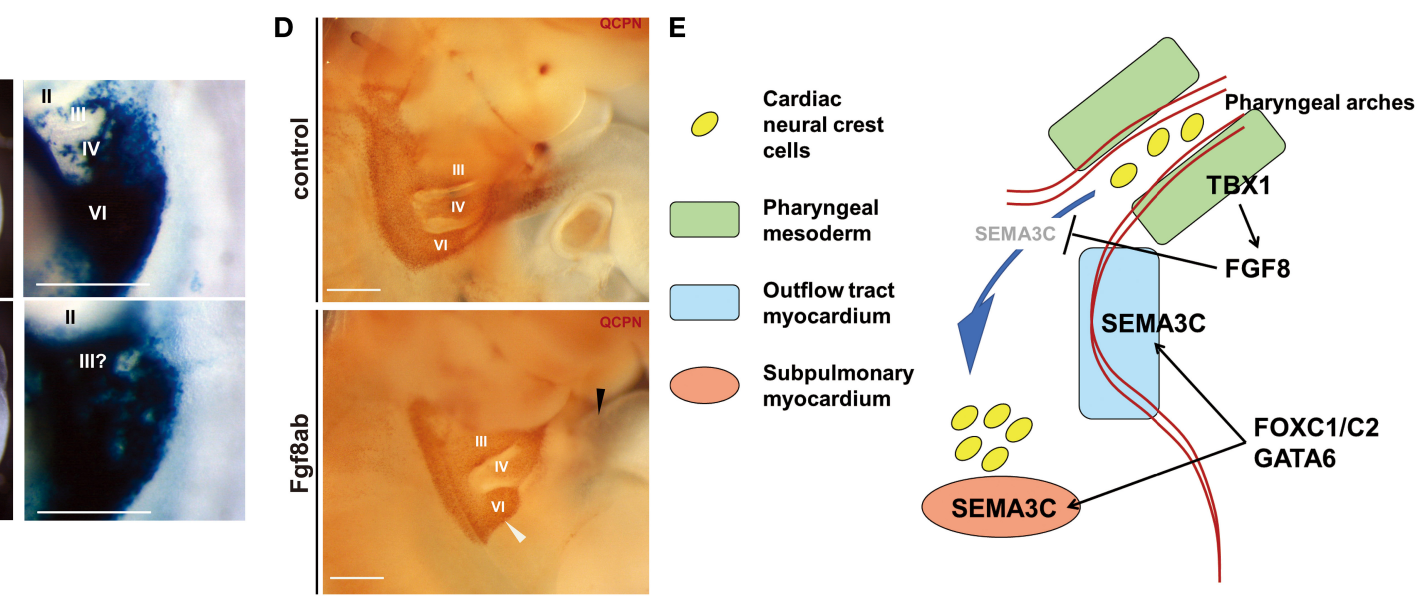

FIGURE 4 | The regulatory mechanism of SEMA3C expression during cardiogenesis by FOXC1, FOXC2, GATA6, and TBX1-FGF8 signaling. (A) Genomic organization of the $5^{\prime}$ mouse Sema3c locus and flanking region. Green boxes indicate exons (Ex), black bars indicate highly conserved regions between human and mouse, and the translation start site (arrow) is designated as nucleotide number zero. Each construct number is indicated on the left. The consensus Fox-binding site is indicated by a green arrowhead. The construct pm- $492 \mathrm{~m}$ has a mutated Fox site in the context of pm-492. Conserved alignments of genomic sequences including the Fox site (box) between human (upper) and mouse (lower) are shown. (B) Right lateral views of the hearts of representative embryos obtained with each construct. Lower lane pictures show higher-magnification views of the heart. (C) LacZ expression in Sema3c int1/3'-lacZ:Tbx1neo/+ (control: upper, left) and Tbx1neo/neo (Tbx1 hypomorphic: lower, left) double-transgenic (tg) embryos at embryonic day (E)10.5, reminiscent of endogenous Sema3c mRNA expression. High-magnification views of the pharyngeal arch region (white box) are shown in the right lane. Enhanced lacZ expression in the pharyngeal arch region of Sema3c int1/3'-lacZ tg:Tbx1neo/neo embryos (lower, right) compared to Sema3c int1/3'-lacZ tg:Tbx1neo/+ embryos (upper, right). (D) Pharyngeal arch regions of chick-quail chimeras with bilateral transplantation of cardiac neural crest cells (cNCCs). Injection of anti-Fgf8 antibody (Fgf8ab) causes less migration of cNCCs from the 6th pharyngeal arch region (white arrowhead) to the outflow tract (black arrowhead) compared to that of the control. (E) A working model for the regulation of SEMA3C in developing cNCCs and second heart field (SHF) progenitor cells. During normal development, TBX1 may restrict the expression of SEMA3C in the SHF along the pharyngeal arch region by blocking ectopic SEMA3C expression in cNCCs via FGF8 signaling. FOXC1, FOXC2, and GATA6 may then synergistically activate the expression of SEMA3C in the SHF during migration into the outflow tract myocardium, leading to differentiation. Panels (A-D) are under a Creative Commons Attribution 4.0 license.

outflow tract and pulmonary trunk (33). These findings are very intriguing because they suggest that deletion of TBX1 in 22q11DS may result in defects of CNC-derived tissues in a non-cell-autonomous fashion through the cellular interaction between $\mathrm{CNC}$ and the SHF. It is believed that TOF results from malalignment of the outflow tract septum, leading to an overriding aorta with malaligned ventricular septal defect $(34,35)$. The developmental defects of CNC is considered to cause malalignment of outflow tract septum, thus leading to TOF. Alternatively, developmental defects of the SHF may cause hypoplasia of the right ventricular outflow tract that may also result in pulmonary stenosis and malalignment of the outflow tract septum with overriding aorta $(34,35)$. Our data about TBX1 in the SHF provides a new insight into the developmental mechanisms underlying TOF where cellular and molecular interaction of CNC and SHF are essential (33). As for PTA in 22q11DS or TBX1 deletion, it is considered that the TBX1-expressing descendants are severely decreased in number, affecting the development and/or migration of CNC cells, thus result in complete absence of the outflow tract septum. Indeed, we recently showed that PTA in mice hypomorphic for Tbx1 might result from agenesis of the pulmonary trunk using $\mathrm{IP}_{3} \mathrm{R} 2$ LacZ mice, in which a $L a c Z$ gene was genetically inserted inframe at the translation initiation site of $I P_{3} R 2$ locus on the mouse genome as a molecular marker (36). This developmental model is consistent of the observation that the outflow tract defects ranging from TOF to PTA are highly associated with 22q11DS (Figure 3). 


\section{EXPLORING THE GENOMIC ARCHITECTURE OF CHD AND THE REGULATORY MECHANISM UNDERLYING THE INTERACTION OF CARDIAC PROGENITOR LINEAGES}

To further elucidate the genomic architecture of CHD, we performed mutation analysis using the genome bank of Japanese patients with non-syndromic CHD, and identified GATA6 as the genetic cause of PTA (37). Mutations in GATA6 disturb the transcriptional regulation of downstream target genes that play an essential role in cardiac development, including semaphorin 3C (SEMA3C) and plexin A2 (PLXNA2). SEMA3C is a neurovascular guiding molecule that functions as a ligand for PLXNA2 and an attractant for CNC cells (38). Mutation of GATA6 eliminates activation of SEMA3C and PLXNA2. Mutation of the GATA sites on the enhancer elements of SEMA3C and PLXNA2 abolished these transactivation activities in the outflow tract myocardium and the $\mathrm{CNC}$ derivatives in the outflow tract. Further analysis of the regulatory mechanism of SEMA3C revealed that a molecular network involving GATA6, FOXC1/2, $T B X 1, S E M A 3 C$, and FGF8 plays an important role in the interaction between SHF and CNC cells (39). Moreover, we found that TBX1 restricts the expression of SEMA3C to the SHF in the pharyngeal arch region by inhibiting ectopic SEMA3C expression in CNC cells during migration via FGF8 signaling, whereas GATA6, FOXC1, and FOXC2 activate the expression of SEMA3C in the SHF in the outflow tract myocardium at the same time. A recent report also showed the positive regulation of SEMA3C expression in the proximal outflow tract by TBX1 (40). This spatial and temporal regulation of SEMA3C expression is essential for proper homing of $\mathrm{CNC}$ cells from the pharyngeal region to the outflow tract. With loss of TBX1, downregulation of TBX1-FGF8 signaling in the pharyngeal region may lead to misexpression of SEMA3C in the migrating CNC cells, resulting

\section{REFERENCES}

1. Nora JJ. Congenital heart disease. In: Nora JJ, Berg K, Nora AH, editors. Genetics in Cardiovascular Diseases: Genetics, Epidemiology and Prevention. New York, NY: Oxford University Press. (1991). p. 53-80.

2. Yamagishi $\mathrm{H}$. Life-long managements for congenital heart diseases: from embryology to adult congenital heart diseases influencing the next generation. Pediatr Cardiol Cardiovasc Surg. (2010) 26:29-32.

3. Akhirome E, Walton NA, Nogee JM, Jay PY. The complex genetic basis of congenital heart defects. Circ J. (2017) 81:629-34. doi: 10.1253/circj.CJ-16-1343

4. Pierpont ME, Brueckner M, Chung WK, Garg V, Lacro RV, McGuire AL, et al. Genetic basis for congenital heart disease: Revisited: A scientific statement from the American Heart Association. Circulation. (2018) 138:e653-e711. doi: 10.1161/CIR.0000000000000606

5. Williams K, Carson J, Lo C. Genetics of congenital heart disease. Biomolecules. (2019) 9:879. doi: 10.3390/biom9120879

6. Srivastava D. Making or breaking the heart: From lineage determination to morphogenesis. Cell. (2006) 126:1037-48. doi: 10.1016/j.cell.2006.09.003

7. Buckingham M, Meilhac S, Zaffran S. Building the mammalian heart from two sources of myocardial cells. Nat Rev Genet. (2005) 6:826-35. doi: $10.1038 / \operatorname{nrg} 1710$ in the failure of their migration with ectopic aggregation, ultimately causing outflow tract defects (Figure 4) (39). Although many other genes are also associated with the regulation of $\mathrm{CNC}$ cell migration, our results regarding the SEMA3C regulatory mechanism provide important evidence of interactions between $\mathrm{CNC}$ and the SHF for the developmental basis of CHD.

\section{CONCLUDING REMARKS}

In recent decades, detailed molecular biological analyses using genetically modified animals and accumulation of solid evidence from human mutation studies have dramatically advanced the understanding of cardiovascular development. In addition, with the recent development of stem cell science, including induced pluripotent stem cells and comprehensive expression analysis procedures using next-generation sequencing, elucidating the more detailed temporal and spatial gene regulatory mechanisms underlying cardiovascular development has become possible with evaluations at the single-cell level $(9,41-43)$. As a future direction for clinical application, detailed elucidation of the genomic architecture of CHD implicated in the mechanism regulating interactions between cells of multiple different origins would facilitate the development of regenerative medicine and/or preventive medicine for complex heart diseases such as CHD.

\section{AUTHOR CONTRIBUTIONS}

All authors listed have made a substantial, direct and intellectual contribution to the work, and approved it for publication.

\section{FUNDING}

This study was supported by the Japan Agency for Medical Research and Development (AMED) under grant number 20ek0109487h0001.
8. Kodo K, Yamagishi H. A decade of advances in the molecular embryology and genetics underlying congenital heart defects. Circ J. (2011) 75:2296-304. doi: 10.1253/circj.cj-11-0636

9. Kodo K, Yamagishi H. Current insights into genetics of congenital heart diseases: GATA and T-box cardiac transcription factors as the hotspot pathogenesis. J Pediatr Cardiol Card Surg. (2017) 1:18-27. doi: 10.24509/JPCCS.170105

10. Kelly RG, Brown NA, Buckingham ME. The arterial pole of the mouse heart forms from FGF10-expressing cells in pharyngeal mesoderm. Dev Cell. (2001) 1:435-40. doi: 10.1016/s1534-5807(01)00040-5

11. Mjaatvedt CH, Nakaoka T, Moreno-Rodriguez R, Norris RA, Kern MJ, Eisenberg CA, et al. The outflow tract of the heart is recruited from a novel heart-forming field. Dev Biol. (2001) 238:97-109. doi: 10.1006/dbio.2001.0409

12. Waldo KL, Kumiski DH, Wallis KT, Stadt HA, Hutson MR, Platt DH, et al. Conotruncal myocardium arises from a secondary heart field. Development. (2001) 128:3179-88.

13. Kirby ML, Gale TF, Stewart DE. Neural crest cells contribute to normal aorticopulmonary septation. Science. (1983) 220:1059-61. doi: 10.1126/science.6844926

14. Hutson MR, Kirby ML. Model systems for the study of heart development and disease. Cardiac neural crest and conotruncal malformations. Semin Cell Dev Biol. (2007) 18:101-10. doi: 10.1016/j.semcdb.2006.12.004 
15. Yamagishi H. Cardiac neural crest. Cold Spring Harb Perspect Biol. (2021) 13:a036715. doi: 10.1101/cshperspect.a036715

16. Arima Y, Miyagawa-Tomita S, Maeda K, Asai R, Seya D, Minoux M, et al. Preotic neural crest cells contribute to coronary artery smooth muscle involving endothelin signalling. Nat Commun. (2012) 3:1267. doi: $10.1038 /$ ncomms 2258

17. Mikawa T, Gourdie RG. Pericardial mesoderm generates a population of coronary smooth muscle cells migrating into the heart along with ingrowth of the epicardial organ. Dev Biol. (1996) 174:221-32. doi: 10.1006/dbio.1996.0068

18. Olivey HE, Svensson EC. Epicardial-myocardial signaling directing coronary vasculogenesis. Circ Res. (2010) 106:818-32. doi: 10.1161/CIRCRESAHA.109.209197

19. Berridge MJ. The inositol trisphosphate/calcium signaling pathway in health and disease. Physiol Rev. (2016) 96:1261-96. doi: 10.1152/physrev.00006.2016

20. Mikoshiba K. Role of IP3 receptor signaling in cell functions and diseases. $A d v$ Biol Regul. (2015) 57:217-27. doi: 10.1016/j.jbior.2014.10.001

21. Uchida K, Aramaki M, Nakazawa M, Yamagishi C, Makino S, Fukuda K, et al. Gene knock-outs of inositol 1,4,5-trisphosphate receptors types 1 and 2 result in perturbation of cardiogenesis. PLOS ONE. (2010) 5:e12500. doi: 10.1371/journal.pone.0012500

22. Nakazawa M, Uchida K, Aramaki M, Kodo K, Yamagishi C, Takahashi $\mathrm{T}$, et al. Inositol 1,4,5-trisphosphate receptors are essential for the development of the second heart field. J Mol Cell Cardiol. (2011) 51:58-66. doi: 10.1016/j.yjmcc.2011.02.014

23. Uchida K, Nakazawa M, Yamagishi C, Mikoshiba K, Yamagishi H. Type 1 and 3 inositol trisphosphate receptors are required for extra-embryonic vascular development. Dev Biol. (2016) 418:89-97. doi: 10.1016/j.ydbio.2016.08.007

24. Yamagishi H. The 22q11.2 deletion syndrome. Keio J Med. (2002) 51:77-88. doi: $10.2302 / \mathrm{kjm} .51 .77$

25. Yamagishi $H$, Srivastava D. Unraveling the genetic and developmental mysteries of 22q11 deletion syndrome. Trends Mol Med. (2003) 9:383-9. doi: 10.1016/s1471-4914(03)00141-2

26. Lindsay EA, Vitelli F, Su H, Morishima M, Huynh T, Pramparo T, et al. Tbx1 haploinsufficieny in the DiGeorge syndrome region causes aortic arch defects in mice. Nature. (2001) 410:97-101. doi: 10.1038/35065105

27. Merscher S, Funke B, Epstein JA, Heyer J, Puech A, Lu MM, et al. TBX1 is responsible for cardiovascular defects in velo-cardio-facial/DiGeorge syndrome. Cell. (2001) 104:619-29. doi: 10.1016/s0092-8674(01)00247-1

28. Jerome LA, Papaioannou VE. DiGeorge syndrome phenotype in mice mutant for the T-box gene, Tbx1. Nat Genet. (2001) 27:286-91. doi: 10.1038/85845

29. Hu T, Yamagishi H, Maeda J, McAnally J, Yamagishi C, Srivastava D. Tbx1 regulates fibroblast growth factors in the anterior heart field through a reinforcing autoregulatory loop involving forkhead transcription factors. Development. (2004) 131:5491-502. doi: 10.1242/dev.01399

30. Garg V, Yamagishi C, Hu T, Kathiriya IS, Yamagishi H, Srivastava D. Tbx1, a DiGeorge syndrome candidate gene, is regulated by sonic hedgehog du ring pharyngeal arch development. Dev Biol. (2001) 235:62-73. doi: 10.1006/dbio.2001.0283

31. Yamagishi $\mathrm{H}$, Maeda J, Hu T, McAnally J, Conway SJ, Kume T, et al. Tbxl is regulated by tissue-specific forkhead proteins through a common Sonic hedgehog-responsive enhancer. Genes Dev. (2003) 17:269-81. doi: 10.1101/gad.1048903

32. Xu H, Morishima M, Wylie JN, Schwartz RJ, Bruneau BG, Lindsay EA, et al. Tbx1 has a dual role in the morphogenesis of the cardiac outflow tract. Development. (2004) 131:3217-27. doi: 10.1242/dev.01174
33. Maeda J, Yamagishi H, McAnally J, Yamagishi C, Srivastava D. Tbx1 is regulated by forkhead proteins in the secondary heart field. Dev Dynam. (2006) 235:701-10. doi: 10.1002/dvdy.20686

34. Thom T, Haase N, Rosamond W, Howard VJ, Rumsfeld J, Manolio $\mathrm{T}$, et al. Heart disease and stroke statistics-2006 update: a report from the american heart association statistics committee and stroke statistics subcommittee. Circulation. (2006) 113:e85-e151. doi: 10.1161/CIRCULATIONAHA.105.171600

35. Siwik ES, Patel CR, Zahka KG. Tetralogy of fallot. In: Allen HD, Gutgesell HP, Clark EB, Driscoll DJ, editors. Moss and Adams' Heart Disease in Infants, Children, and Adolescents Including the Fetus and Young Adult. Philadelphia: Lippincott Williams \& Wilkins (2001). p. 880-902.

36. Ishizaki-Asami R, Uchida K, Tsuchihashi T, Shibata A, Kodo K, Emoto K, et al. Inositol 1,4,5-trisphosphate receptor 2 as a novel marker of vasculature to delineate processes of cardiopulmonary development. Dev Biol. (2020) 458:237-45. doi: 10.1016/j.ydbio.2019.11.011

37. Kodo K, Nishizawa T, Furutani M, Arai S, Yamamura E, Joo K, et al. GATA6 mutations cause human cardiac outflow tract defects by disrupting semaphorin-plexin signaling. Proc Natl. Acad Sci USA. (2009) 106:13933-8. doi: 10.1073/pnas.0904744106

38. Toyofuku T, Yoshida J, Sugimoto T, Yamamoto M, Makino N, Takamatsu $\mathrm{H}$, et al. Repulsive and attractive semaphorins cooperate to direct the navigation of cardiac neural crest cells. Dev Biol. (2008) 321:251-62. doi: 10.1016/j.ydbio.2008.06.028

39. Kodo K, Shibata S, Miyagawa-Tomita S, Ong SG, Takahashi H, Kume T, et al. Regulation of Sema3c and the interaction between cardiac neural crest and second heart field during outflow tract development. Sci Rep. (2017) 7:6771. doi: 10.1038/s41598-017-06964-9

40. Théveniau-Ruissy M, Dandonneau M, Mesbah K, Ghez O, Mattei MG, Miquerol L, et al. The del22q11.2 candidate gene Tbx1 controls regional outflow tract identity and coronary artery patterning. Circ Res. (2008) 103:142-8. doi: 10.1161/circresaha.108.172189

41. Kodo K, Ong SG, Jahanbani F, Termglinchan V, Hirono K, InanlooRahatloo $\mathrm{K}$, et al. iPSC-derived cardiomyocytes reveal abnormal TGF- $\beta$ signalling in left ventricular non-compaction cardiomyopathy. Nat Cell Biol. (2016) 18:1031-42. doi: 10.1038/ncb3411

42. Zhang JZ, Termglinchan V, Shao NY, Itzhaki I, Liu C, Ma N, et al. A human iPSC double-reporter system enables purification of cardiac lineage subpopulations with distinct function and drug response profiles. Cell Stem Cell. (2019) 24:802-11.e5. doi: 10.1016/j.stem.2019.02.015

43. de Soysa TY, Ranade SS, Okawa S, Ravichandran S, Huang Y, Salunga HT, et al. Single-cell analysis of cardiogenesis reveals basis for organ-level developmental defects. Nature. (2019) 572:120-4. doi: 10.1038/s41586-019-1414-x

Conflict of Interest: The authors declare that the research was conducted in the absence of any commercial or financial relationships that could be construed as a potential conflict of interest.

Copyright ( $\odot 2021$ Kodo, Uchida and Yamagishi. This is an open-access article distributed under the terms of the Creative Commons Attribution License (CC BY). The use, distribution or reproduction in other forums is permitted, provided the original author(s) and the copyright owner(s) are credited and that the original publication in this journal is cited, in accordance with accepted academic practice. No use, distribution or reproduction is permitted which does not comply with these terms. 